\title{
PREVALANCE OF ENDOPARASITES IN HOUSE CROW (CORVUS SPLENDENS) FROM DIFFERENT AGROECOSYSTEMS OF LUDHIANA, PUNJAB
}

\author{
CHANDAN SHARMA \& NISHA VASHISHAT
}

\author{
Department of Zoology, Punjab Agricultural University, Ludhiana, Punjab, India
}

\begin{abstract}
Parasitism is one of the major health related problems, in the avian species. Thus parasitological examination for endoparasites is essential to access the health status of birds and their transmission to humans, which can cause infections and diseases. The importance of wild birds as potential vectors of disease has received recent renewed empirical interest, especially regarding human health. Therefore, the present study was conducted to examine the prevalence of different parasites in the excreta samples of the House Crow (Corvus splendens), with zoonotic potential. Fresh fecal samples were collected from different agrifield and residential sites of Ludhiana. The collected samples of 21 droppings, 3 from each selected site were preserved in sterile containers. The samples were examined for prevalence of eggs and adults of endoparasites by fecal flotation technique. It was found that overall $42.6 \%$ samples were positive for parasites (50\% of agrifield samples and 33.33\% of residential samples). The samples were observed to contain two different genera of parasites, including Strongyle eggs and Tapeworm (Class-Cestoda) with prevalences of 38.09\% and 4.76\% respectively. The reason behind the prevalence of parasites may be attributed to the feeding habits of bird or difference in habitat structure. The different genera of parasites can cause infection in bird and could infect humans who came in contact with crow droppings.

KEYWORDS: Agro Ecosystem, Birds, House Crow \& Parasites
\end{abstract}

Received: Jul 10 12, 2017; Accepted: Jul 25, 2017; Published:Jul 31, 2017; Paper Id.: IJASRAUG201774

\section{INTROUDUCTION}

Birds are susceptible to parasites just as mammals and reptiles are. Birds can be infested with internal parasites such as worms, and external parasites like mites etc. Juvenile birds are expected to be more exposed to parasitic infections than older ones and they may also suffer from a lack of immunity. Birds are host to a variety of parasites which exhibit a disease array of form and life history, and where obligate and non-obligate taxa are recognized as vector of pathogens and diseases (Delgado \& French, 2012). The parasite species diversity and parasitic infections in birds are probably higher in tropical areas (Bennett et al, 1993).

An overriding concern of the public in most areas with high densities of birds is the possibility of disease transmission to humans through direct contact with avian feacal material (Feare et al, 1999). Crows and Cattle Egrets are two species of wild birds that recently have increased significantly and have become highly adaptable to the urban environment (Aruji et al, 2004). They may carry causal agents of zoonotic inactivity and their fecal shedding may contaminate the environment (Aruji et al, 2004). According to many researchers (Rappole et al, 2000; Krauss et al, 2004; Tsiodras et al, 2008) migratory birds may play a role in the spread of zoonotic agents and impact and contaminate water. However, recently there is evidence supporting direct pathogen transmission from wild birds to humans (Tsiodras et al, 2008). 
The bird dropping is the most common way by which the diseases are passed from the bird to humans. As bird feces or the contaminated soil, it rests on, dries or is disturbed, microscopic pieces break off and become airborne. These airborne particles can contain dormant fungi or bacteria. When breathed into the lungs, the warm, moist environment of the lung lining provides a breeding ground for the infectious agents. The House Crow is a public health hazard and can be a threat to humans because of being a synanthropic species.

As it is important to identify and control parasite species, that are capable of producing diseases in birds, there is a need for parasitological studies on avian species. In order to give further insights, the present study was designed to examine the prevalence of parasites detectable by fecal flotation technique in the fresh excreta samples of the House Crow (Corvus splendens) from different habitats of Ludhiana district of Punjab.

\section{METHODS}

\section{Sample Collection}

The roosting, foraging and nesting sites of the House Crow (Corvus splendens) was founded in agrifield, orchard and vegetable farms of PAU, Ludhiana and in different residential areas of Ludhiana city for the collection of fresh excreta samples. The wet excreta samples of the House Crow were collected from selected sites. The fresh samples were collected on three consecutive days in August, 2016 (New Delhi GMT/UTC + 05:30; daytime: 13h 10min, sunrise at 5:50 am, sunset at 7:00 pm) between 6:00 to 8:00 am from different sites in sterile plastic bags. The plastic bags with excreta samples were labeled with the name of site, time and date of collection and stored in refrigerator.

\section{Laboratory Procedure}

The faecal flotation technique was performed within 12 hours of collection of samples. The freshly prepared sodium chloride solution was used. Fresh fecal samples were then mixed well with salt solution with high density that helps the heavier parasite eggs to float on a solution which makes it easier to examine the prevalence of parasites under microscope. Then the prepared slides were microscopically screened at 100X and $400 \mathrm{X}$ magnifications. Parasites were identified on the basis of their morphological characteristics.

\section{RESULTS}

Overall 21 samples, three from each site (4 agrifield sites, 3 residential sites) were examined. Out of these, 9 samples were positive (i.e. the samples which contain atleast one parasite). Out of 12 faecal samples from different agrifield area 6 samples (50\%) were positive. Samples collected from residential sites out of 9, three samples (33.33\%) were positive for parasites (Table 1,2).

Table 1: Distribution of Parasites in Fresh Excreta Samples of House Crow (Corvus splendens) from Different Habitat Sites of Ludhiana District

\begin{tabular}{|c|c|c|c|c|}
\hline \multirow[t]{2}{*}{ S. No. } & \multirow[t]{2}{*}{ Site } & \multirow[t]{2}{*}{$\begin{array}{c}\text { No. of Samples } \\
\text { Examined }\end{array}$} & \multicolumn{2}{|c|}{$\begin{array}{l}\text { No. of Samples } \\
\text { Positive for } \\
\text { Parasites }\end{array}$} \\
\hline & & & Strongyles & Cestode \\
\hline Site 1 & \multirow{4}{*}{$\begin{array}{l}\text { Agrifield } \\
\text { sites }\end{array}$} & 3 & 2 & ND \\
\hline Site 2 & & 3 & ND & ND \\
\hline Site 3 & & 3 & 2 & 1 \\
\hline Site 4 & & 3 & 1 & ND \\
\hline Site 5 & Residential & 3 & 2 & ND \\
\hline
\end{tabular}




\begin{tabular}{|c|c|c|c|c|}
\hline Site 6 & \multirow{2}{*}{ sites } & 3 & ND & ND \\
\cline { 3 - 5 } Site 7 & & 3 & 1 & ND \\
\hline Total & & $\mathbf{2 1}$ & $\mathbf{8}$ & $\mathbf{1}$ \\
\hline
\end{tabular}

ND refers to parasites not detected

Table 2: Percentage Prevalence of Parasites in Excreta Samples of House Crow (Corvus splendens) from Different Habitat Sites of Ludhiana District

\begin{tabular}{|c|l|l|l|}
\hline \multirow{2}{*}{ S. No. } & \multirow{2}{*}{$\begin{array}{c}\text { Sites of Sample Selection } \\
\text { (No. of Samples Examined) }\end{array}$} & \multicolumn{2}{|c|}{$\begin{array}{c}\text { Percentage Prevalence of } \\
\text { Parasites in Positive } \\
\text { Samples }\end{array}$} \\
\cline { 3 - 4 } & & Strongyles & Cestode \\
\hline 1 & Agrifield sites (12) & $41.7 \%$ & $8.33 \%$ \\
\hline 2 & Residential sites (9) & $33.33 \%$ & ND \\
\hline
\end{tabular}

ND refers to parasites not detected

The selected sites were having different habitat structure, presence of different food material, waste material (dump and garbage) etc. The cestodes were found only in samples from agrifield areas and the nematode eggs (strongyles) were detected in samples from both agrifield and residential areas. The nematode eggs and cestode were detected in the fresh excreta samples of the House Crow (Corvus splendens) with a prevalence of $38.09 \%$ and $4.76 \%$ respectively from selected sites (Figure 1).

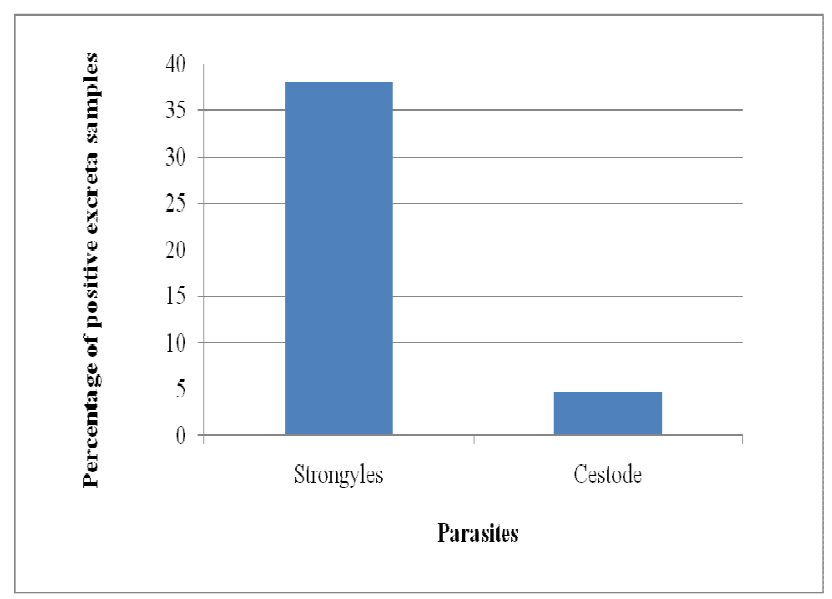

Figure 1: Percentage Prevalence Lof Parasites in Excreta samples of House Crow (Corvus splendens) from Different Habitat Sites of Ludhiana District

The parasites were identified on the basis of their morphological characters. The strongyle eggs were seen under microscopic magnification of 400X. The strongyles are nematode worms of the family Strongylidae and order Strongylida. The strongyle eggs were thin shelled, barrel shaped side walls having broad ellipse. The size was approximately $80 \mu \mathrm{m}$. The various developmental stages can be seen under fine microscope. The cestode or tapeworm was identified on the basis of its flattened long ribbon-like segmented body. Few broken segments were seen in excreta sample that confirmed the presence of parasite in the sample (Figure 2). 


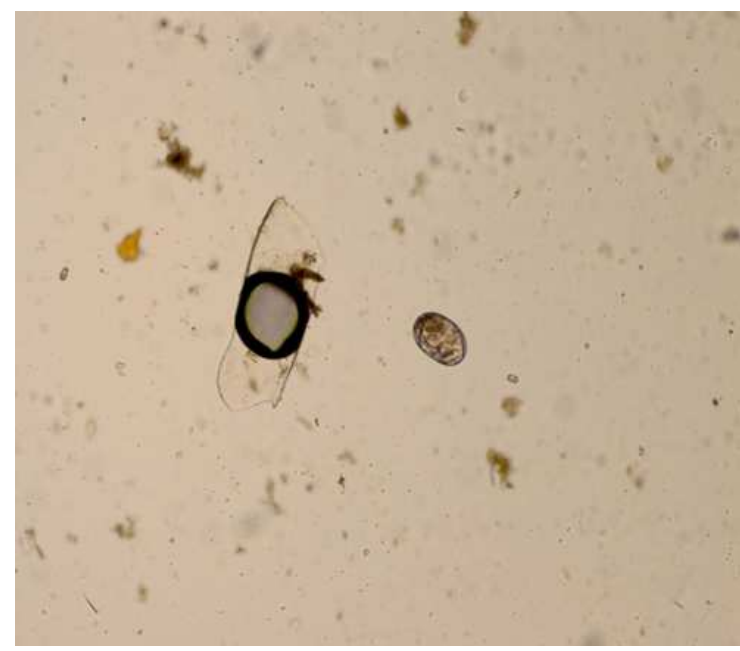

Figure 2(a): Strongle Egg in Feacal Sample of House Crow from Residential Area

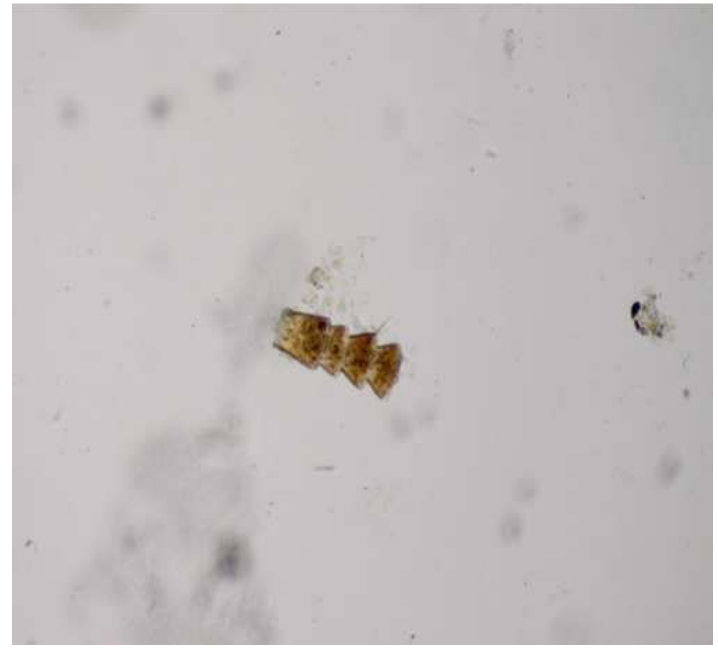

Figure 2(b): Cestode Segments in Feacal Sample of House Crow form Agrifield Area

\section{DISCUSSIONS}

The present study showed that the parasites were common in House Crow (Corvus splendens) as the samples were $42.6 \%$ positive to parasite prevalence. Wild birds are more likely to have a problem with parasites because of their increased risk of exposure. All of these diseases are transmitted from one bird to another at feeding stations, especially when overcrowding occurs (Clark et al, 2016). Two different genera were found in the parasitological analysis in excreta samples. The most frequently found eggs were those of strongyles (nematode worms). These are small, fine worms that occur in the caeca (Trichostrongylus) and gizzard (Amidostomum, Epomidiostomum) but also in the respiratory tract (Cyathostoma, Syngamus) of birds. Earlier it has been reported that the heavy infections with caecal and gizzard strongyles can lead to serious disease mostly in red grouses (Tompkins, 2009) and waterfowl within the family Anatidae (Fedynich \& Thomas, 2009) respectively. Viney \& Lok (2007) quoted that Strongyloides was the genus containing about 50 species of gastrointestinal parasites of vertebrates, infection birds in addition to mammals, reptiles and amphibians. Nematode eggs have been most commonly found in bird faeces or in poultry.

Among the Psittacine groups of birds studied at Arignar Anna Zoological Park, Vandalur, eggs of strongyles were encountered mainly as mixed infections along with Ascaridia sp. and Caillaria sp. regarding to this, Papini et al, (2012) reported that during a survey in 63 pet birds and 83 zoo birds, strongyles were observed at the rate of $5.5 \%$. The development of the parasite can vary greatly depending on the conditions mainly temperature and humidity. The eggs and larvae of nematode (strongyles) can both tolerate periods of low temperature but neither can survive in hot and dry weather. In perfect conditions with high humidity and temperatures exceeding $15^{\circ} \mathrm{C}$ most eggs will hatch within 24 hours. The weather conditions at the time of sample collection and examination of the present studies was supportive in the growth of parasite eggs being a reason for the prevalence of these parasites in excreta samples of bird. The other parasite found was custard (Taenia spp.) that can cause many problems in a bird's stomach and intestines, but also affects the normal functions of other organs. Tapeworms, is a type of parasite which affects the bird's digestive tract. The tapeworm requires intermediate host. Either proglottids or whole worms may be noted in the feces. In the earlier studies Tully et al (2000) defined that especially in the group of parakeets the tapeworm were the commonest observed parasite. Generally infections are non-pathogenic, but a large number of worms can cause infection. The bird microbiota has been 
demonstrated to be affected by many different factors, such as infections and general health status, diet, and local parasitic communities in an environment (Rzymski et al, 2017).

The parasites must have infected the crows when they fed on refuse around human habitation, insects and other edible things. Wild birds can acquire enteropathogens by feeding on raw sewage and garbage and can spread these agents to humans directly or by contaminating commercial operations (Reed et al, 2003). Wild birds are important to public health because they carry emerging zoonotic pathogens, either as a reservoir host or by dispersing infected arthropod vectors (Albin et al, 2014; Ehsan et al, 2015). The current study is the first to report the occurrence of strongyles and cestodes in the House Crow excreta samples in this area. In this study the prevalence of parasites was reported in 50\% of samples from agrifield area which was comparatively higher than the samples of residential areas i.e. $33.33 \%$. This may be because of the more diverse food availability in agrifield areas.

\section{CONCLUSIONS}

It is concluded from the findings of the present study that the introduction of parasitological examinations is needed in the field of ornithology because most of the bird diseases and infections are caused by the endoparasites that can cause infections to the other animals and humans too who came in contact with bird droppings.

\section{REFERENCES}

1. Albini, K, Sigrist, G. \& Keller, H. (2014). Shedding of zoonotic pathogens and analysis of stomach contents in great cormorants (Phalacrocorax carbo sinensis) from Switzerland between 2007 and 2012. Schweiz. Arch Tierheilkd 156, 389-394.

2. Aruji, Y, Tamura, K, Sugita, S. \& Adachi, Y. (2004). Intestinal microflora in 45 crows in Ueno Zoo and the in vitro susceptibilities of 29 E.coli isolates to 14 antimicrobial agents. Journal of Veterinary Medical Science, 66(10), 1283-1286.

3. Bennett, G. F, Peirce, M. A, \& Ashford, R. W. (1993). Avian haematozoa: mortality and pathogenicity. Journal of Natural History, 27, 993-1001.

4. Clark, N. J, Clegg, S. M. \& Klaassen, M. (2016). Migration strategy and pathogen risk: non-breeding distribution drives malaria prevalence in migratory waders. Oikos, 125, 1358-1368.

5. Delgado, V. \& French, K. (2012). Parasite-bird interactions in urban areas: current evidence and emerging questions. Landscape and Urban Planning, 105 (1-2), 5-14.

6. Ehsan, A, Geurden, T, Casaert, S, Paulussen, J, De Coster, L, Schoemaker, T, Chalmers, R, Grit, G, Vercruysse, J \& Claerebout, E. (2015). Occurrence and potential health risk of Cryptosporidiumand Giardia in different water catchments in Belgium. Environmental Monitoring and Assessment, 187 (2), 6.

7. Feare, C. J, Sanders, M. F, Blasco, R. \& Bishop, J. D. (1999). Canada goose (Branta canadensis) droppings as a potential source of pathogenic bacteria. Journal of the Royal Society of Health, 119(3), 146-155.

8. Fedynich, Allan \& Thomas, Nancy. (2009). "Amidostomum and Epomidiostomum," in Parasitic Diseases of Wild Birds (pp. 355-375), John Wiley \& Sons, Oxford, UK.

9. Krauss, S, Walker D, Pryor P, Niles L, Chenghong L, Hinshaw V. \& Webster R. (2004). Influenza A virus- 494 waterbirds of migrating wild aquatic birds in North America. Vector-Borne and Zoonotic Diseases, 4, 177-189.

10. Papini, R, Girivetto, M, Marangi, M, Mancianti, F. \& Giangaspero, A. (2012). Endoparasite Infections in Pet and Zoo Birds in Italy. Scientific World Journal, DOI: 10.1100/2012/253127. 
11. Rappole, J. H, Derrickson S. R. \& Hubálek, Z. (2000). Migratory birds and spread of West Nile virus in the Western Hemisphere. Emerging Infectious Diseases, 6, 319-328.

12. Reed, K. D, Meece, J. K, Henkel, J. S. \& Sanjay, K. S. (2003). Birds, migration and emerging zoonoses: West Nile virus, Lyme disease, influenza A and enteropathogens. Clinical Medicine and Research 1, 5-12.

13. Rzymski, P, Stodkowicz-Kowalska, A, Klimaszyk, P, Solarczyk P. \& Poniedziatek, B. (2017). Screening of protozoan and microsporidian parasites in feces of great cormorant (Phalacrocorax carbo). Environmental Science and Pollution Research, 24 (10), 9813-9819.

14. Tompkins, Daniel M. (2009). Trichostrongylus in Parasitic Diseases of Wild Birds (pp. 316-325), JohnWiley \& Sons, Oxford, $U K$.

15. Tsiodras, S, Kelesidis T, Kelesidis I, Bauchinger U. and Falagas M. E. (2008). Human infections associated with wild birds. Journal of Infection, 56, 83-98.

16. Tully, T. N, Lawton, M. P. C. and Dorrestein, G. M. (2000). Avian Medicine, Butterworth Heinemann, Oxford Press.

17. Viney, M. E. \& Lok, J. B. (2007). Strongyloides spp. In The C. elegans Research community (ed.) WormBook, 23, 1-15. 